\title{
Meningkatkan Hasil Belajar Matematika Melalui Pendekatan Contextual Teaching Learning (CTL) Materi Pecahan Kelas III MI AL MA'ARIF Kota Sorong
}

\author{
Hartini \\ MI AL-MA’ARIF Kota Sorong \\ Email: namakuria@gmail.com
}

\begin{abstract}
The aim of this study is to improve the students' mathematic achievement for decimal fraction material by using Contextual Teaching and Learning (CTL) at class III of MI AL-MA'ARIF Sorong City. This study is the result of a collaboration classroom action research. This study performed for 2 cycles. Each cycle had two meeting. The subject of this study is students at class III of MI AL-MA'ARIF Academic year 2016/22017. The techniques of collecting data were test, observation, documentation and field note. The result of study showed that (1) the use of CTL can improve teachers' skill on the first cycle, that was $84 \%$ and improved become $93 \%$ at the second cycle. (2) The use of CTL can improve students' activity, that was on the first cycle $70.5 \%$ and improved become $85.5 \%$ on the second cycle. (3) The result of students' achievement at the first and second cycle can improve in the learning process, that was participation in explaining at the first cycle was $63 \%$ and improved become $82 \%$ on the second cycle. From the result of this study, it can be concluded that the use of CTL can improve the students' achievement. Keywords: Achievement, Contextual Teaching and Learning, Mathematic, fraction, MI Al Ma'arif Sorong City
\end{abstract}

\begin{abstract}
Abstrak: Penelitian ini bertujuan untuk meningkatkan hasil belajar siswa kelas III MI AL-MA'ARIF Kota Sorong pada mata pelajaran Matematika dengan pokok Pecahan dengan menggunakan pendekatan Contextual Teaching Learning (CTL). Penelitian ini merupakan penelitian tindakan kelas kolaboratif. Subjek dalam penelitian ini siswa kelas III MI AL-MA'ARIF Kota Sorong Tahun Ajaran 2016/2017. Penelitian ini dengan menggunakan dua siklus, setiap siklus terdiri dari dua kali pertemuan Teknik pengumpulan data menggunakan tes, pengamatan (observasi), dokumentasi, dan catatan lapangan. Hasil penelitian menunjukkan bahwa : (1) Keterampilan guru dalam pembelajaran matematika melalui pendekatan CTL meningkat. Pada siklus I diperoleh rata-rata persentase 84\% (baik). Pada siklus II mengalami peningkatan rata-rata persentase 93\% (baik sekali). (2) Aktivitas siswa pada pembelajaran matematika melalui pendekatan CTL meningkat. Pada siklus I rata-rata persentase $70,5 \%$ (baik). Pada siklus II persentase aktivitas siswa menjadi 85,5\% (baik sekali). (3) Hasil belajar siswa pada siklus I dan II mengalami peningkatan. Pada siklus I ketuntasan belajar klasikal 63\% (cukup) dan meningkat pada siklus II menjadi $82 \%$ (baik). Hal ini menunjukkan bahwa persentase ketuntasan belajar klasikal pada siklus II $>75 \%$ sehingga dinyatakan berhasil. Simpulan dari penelitian ini adalah penerapan pendekatan CTL dapat meningkatkan kualitas pembelajaran matematika dengan menggunakan materi pecahan di MI AL-MA’ARIF Kota Sorong.
\end{abstract}

Kata kunci : Hasil Belajar, CTL, Matematika, pecahan, MI Al Ma’arif Kota Sorong 


\section{Pendahuluan}

Pendidikan matematika merupakan salah satu fondasi dari kemampuan sains dan teknologi. Pemahaman terhadap matematika, dari kemampuan yang bersifat keahlian sampai kepada pemahaman yang bersifat apresiatif akan berhasil mengembangkan kemampuan sains dan teknologi yang cukup tinggi (Buchori, 2001:120-121). Mengingat pentingnya matematika dalam pengembangan generasi melalui kemampuan mengadopsi maupun mengadakan inovasi sains dan teknologi di era globalisasi, maka tidak boleh dibiarkan adanya anak-anak muda yang buta matematika. Kebutaan matematika yang dibiarkan menjadi suatu kebiasaan, membuat masyarakat kehilangan kemampuan berpikir secara disipliner dalam menghadapi masalah - masalah nyata.

Pengajaran matematika mempunyai tujuan yang sangat luas, salah satu tujuannya adalah agar siswa memiliki keterampilan menghubungkan matematika dengan kehidupan sehari-hari dan menerapkannya dalam soal-soal. Dengan demikian penggunaan model pembelajaran CTL perlu diberikan oleh guru dalam proses belajar, agar dapat mencapai hasil belajar yang lebih baik. Belajar dengan model pembelajaran CTL akan mampu mengembangkan kemampuan siswa dalam menyelesaikan masalahmasalah serta mengambil keputusan secara objektif dan rasional. Disamping itu juga akan mampu mengembangkan kemampuan berfikir kritis, logis, dan analitis. Karena itu siswa harus benar-benar dilatih dan dibiasakan berfikir secara kritis dan mandiri. Dengan menggunakan model pembelajaran CTL diharapkan siswa mampu menyelesaikan soal-soal matematika.

Penerapan model pembelajaran CTL dalam pembelajaran matematika khususnya pokok bahasan pecahan melibatkan siswa untuk dapat berperan aktif dengan bimbingan guru, agar peningkatan kemampuan siswa dalam memahami konsep dapat terarah lebih baik.

Untuk mengatasi masalah yang terjadi pada pembelajaran matematika kelas III MI AlMa'arif Kota Sorong akan dilakukan penelitian tindakan kelas (PTK). PTK ini dilaksanakan oleh guru dengan tujuan untuk memperbaiki dan meningkatkan kualitas pembelajaran dalam memecahkan masalah di sekolah, yaitu dengan menerapkan pendekatan CTL pada materi Pecahan.

\section{Metode Penelitian}

\subsection{Desain Penelitian}

Penelitian ini adalah Penelitian Tindakan Kelas, peneliti menggunakan rancangan Penelitian Tindakan Kelas sebagai berikut :

1) Perencanaan, yang meliputi: menemukan daftar permasalahan pembelajaran di kelas, menetapkan fokus masalah yang akan diperbaiki, menetapkan alternatif tindakan untuk pemecahan masalah, merencanakan pembelajaran berbasis CTL yang akan diterapkan dalam 
KBM, menyusun silabus sesuai dengan pembelajaran yang direncanakan, menyusun RPP sesuai dengan indikator yang telah ditetapkan dan skenario pembelajaran matematika dengan pendekatan CTL, menyiapkan alat peraga, media pembelajaran, dan sumber belajar, menyiapkan alat evaluasi tes tertulis, dan lembar kerja siswa, menyiapkan lembar observasi untuk mengamati aktivitas siswa dan keterampilan guru.

2) Tindakan, yang meliputi: Pelaksanaan tindakan ini merupakan penerapan tindakan yang mengacu pada scenario tindakan yang telah direncanakan. Pelaksanaan PTK ini direncanakan dalam dua siklus. Masing-masing siklus terdiri dari dua kali pertemuan.

3) Observasi, yang meliputi: Kegiatan observasi dilaksanakan secara kolaboratif dengan teman sejawat untuk mengamati keterampilan guru dan aktivitas siswa selama pembelajaran dengan menerapkan pendekatan CTL.

4) Refleksi, yang meliputi: Mengkaji proses pembelajaran yaitu keterampilan guru, aktivitas siswa, serta hasil belajar siswa, apakah sudah efektif dengan melihat ketercapaian dalam indikator keberhasilan pada siklus pertama, serta mengkaji kekurangan dan membuat daftar permasalahan

\subsection{Tempat Penelitian}

Penelitian ini dilakukan di MI Al-Ma'arif Kota Sorong Kecamatan Kladufu Kota Sorong, Papua Barat.

\subsection{Teknik Pengumpulan Data}

Teknik pengumpulan data yang digunakan dalam penelitian ini, sesuai dengan desain penelitian yang telah diuraikan:

1) Tes

Tes dilakukan untuk mengumpulkan informasi tentang hasil belajar siswa melalui pendekatan CTL pada mata pelajaran metematika. Tes dilaksanakan pada setiap tindakan.

2) Pengamatan (Observasi)

Pengamatan dilakukan untuk melihat secara langsung proses pembelajaran matematika dengan menggunakan pendekatan CTL.

3) Dokumentasi

Metode dokumentasi dalam penelitian ini digunakan untuk mengetahui keterampilan guru dan aktivitas siswa dalam pembelajaran matematika melalui pendekatan CTL.

4) Catatan Lapangan

Catatan lapangan ini digunakan untuk mencatat segala peristiwa penting yang terjadi sehubungan dengan tindakan guru selama kegiatan pembelajaran. Catatan lapangan tersebut 
bertujuan untuk melihat tindakan, membantu peneliti apabila menemui kesulitan, dan sebagai solusi untuk memecahkan masalah agar dapat melakukan refleksi

\subsection{Teknik Analisis Data}

a. Data kuantitatif berupa hasil belajar kognitif secara klasikal yang dianalisis dengan menggunakan teknik analisis deskriptif dengan menentukan mean atau rerata

$$
\begin{array}{r}
\bar{X}= \\
- \\
\\
\sum N
\end{array}
$$

b. Data kualitatif berupa data hasil observasi keterampilan guru dan aktivitas siswa dalam pembelajaran CTL, serta hasil catatan lapangan dianalisis dengan analisis deskriptif kualitatif

\section{Hasil Penelian dan Pembahasan}

\subsection{Hasil Penelitian}

Proses Pembelajaran Siklus I dilaksanakan dalam dua kali pertemuan dengan menggunakan pendekatan Contextual Teaching and Learning. Indikator keberhasilan yang ditetapkan adalah capaian ketuntasan belajar klasikal sebanyak $75 \%$ dengan KKM 60. Dari tabel tersebut dapat kita lihat siswa yang telah tuntas (mencapai dan melampaui KKM) sebanyak 17 siswa. Ketuntasan belajar klasikal sebanyak 63\% jadi belum mencapai ketuntasan klasikal. Refleksi tindakan pada siklus I ini difokuskan pada masalah yang muncul selama tindakan berlangsung. Berdasarkan deskripsi hasil observasi siklus I ditemukan permasalahan dalam pembelajaran sebagai berikut.

a. Hasil tes menunjukan bahwa masih ada $37 \%$ siswa yang belum tuntas. Ketuntasan belajar klasikal hanya 63\% sehingga belum sesuai dengan yang diharapkan.

b. Siswa kurang berani bertanya dan berani menjawab pertanyaan guru.

c. Siswa kurang berani mengemukakan pendapat.

d. Siswa kurang termotivasi untuk dapat menyajikan temuannya untuk dipaparkan di depan kelas.

e. Ada beberapa siswa yang belum dapat bekerjasama dengan teman kelompoknya sehingga mendapatkan hasil yang kurang baik. Pada saat tes individual masih ada siswa yang mengerjakan dan mengumpulkan lembar evaluasi tidak tepat pada waktu yang telah ditentukan. Untuk lebih jelasnya hasil belajar siswa pada siklus I dapat dilihat dalam tabel di bawah ini. 
Tabel 1. Distribusi frekuensi hasil belajar siswa siklus I

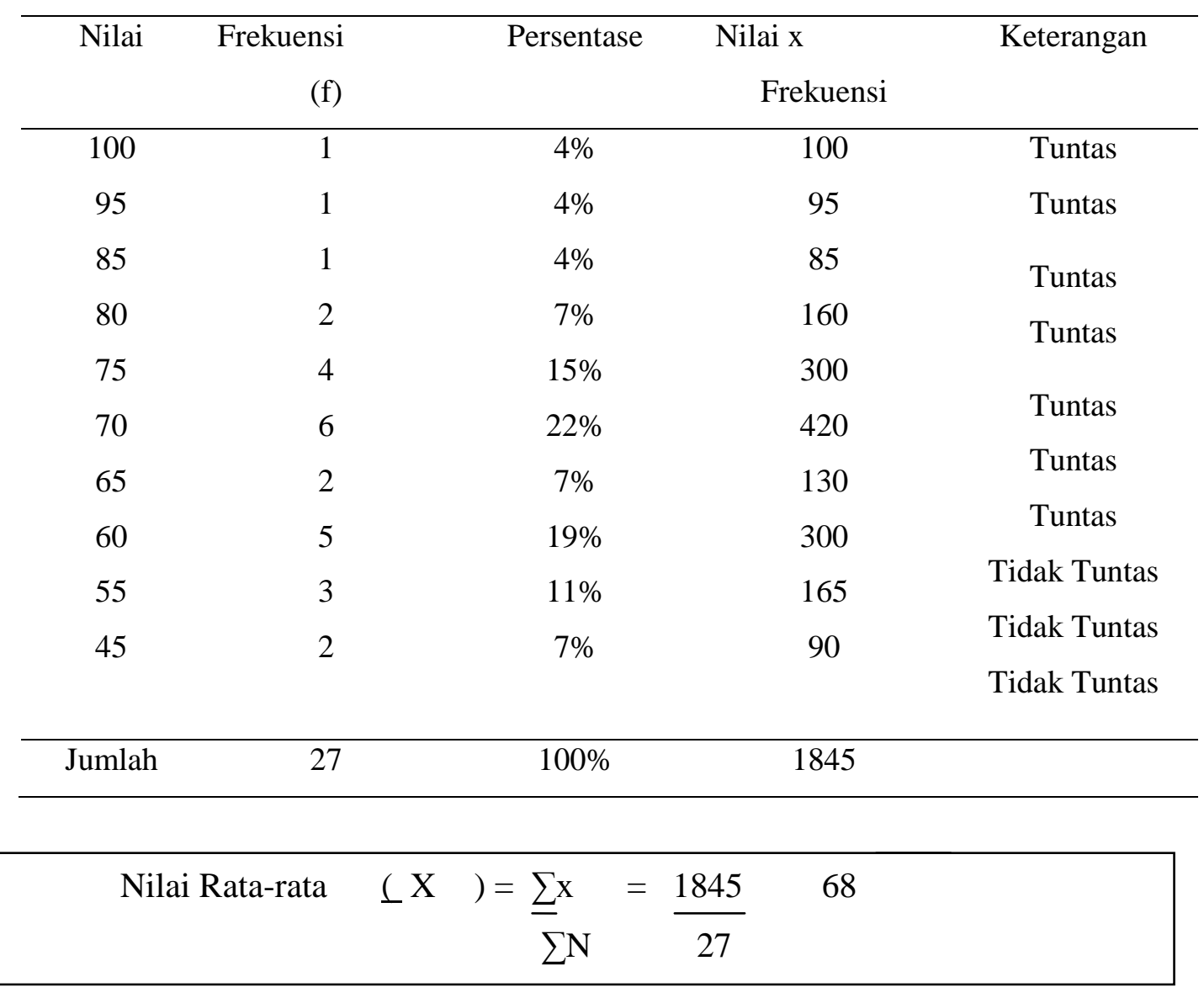

Siklus II dilaksanakan dalam dua kali pertemuan, Berdasarkan deskripsi hasil observasi siklus II ditemukan hasil refleksi sebagai berikut,

1) Hasil tes menunjukkan bahwa $82 \%$ siswa mi al-ma'arif Kota Sorong telah tuntas belajar.

2) Siswa mulai terbiasa untuk melakukan belajar kelompok dan bekerjasama untuk memecahkan masalah yang ada.

3) Siswa sudah berani bertanya, menjawab pertanyaan, dan mengemukakan pendapat tanpa ditunjuk oleh guru.

4) Siswa sudah berani menyajikan dan menjelaskan hasil temuannya di depan kelas.

5) Masih ada beberapa siswa yang tidak disiplin waktu

\subsection{Pembahasan}

Berdasarkan refleksi pada pembelajaran siklus II, hasil tes dan lembar observasi keterampilan guru dan aktivitas siswa telah mancapai indikator. Untuk lebih jelasnya hasil belajar siswa pada siklus II dapat dilihat dalam diagram batang di bawah ini:. 
Diagram hasil belajar siswa siklus II

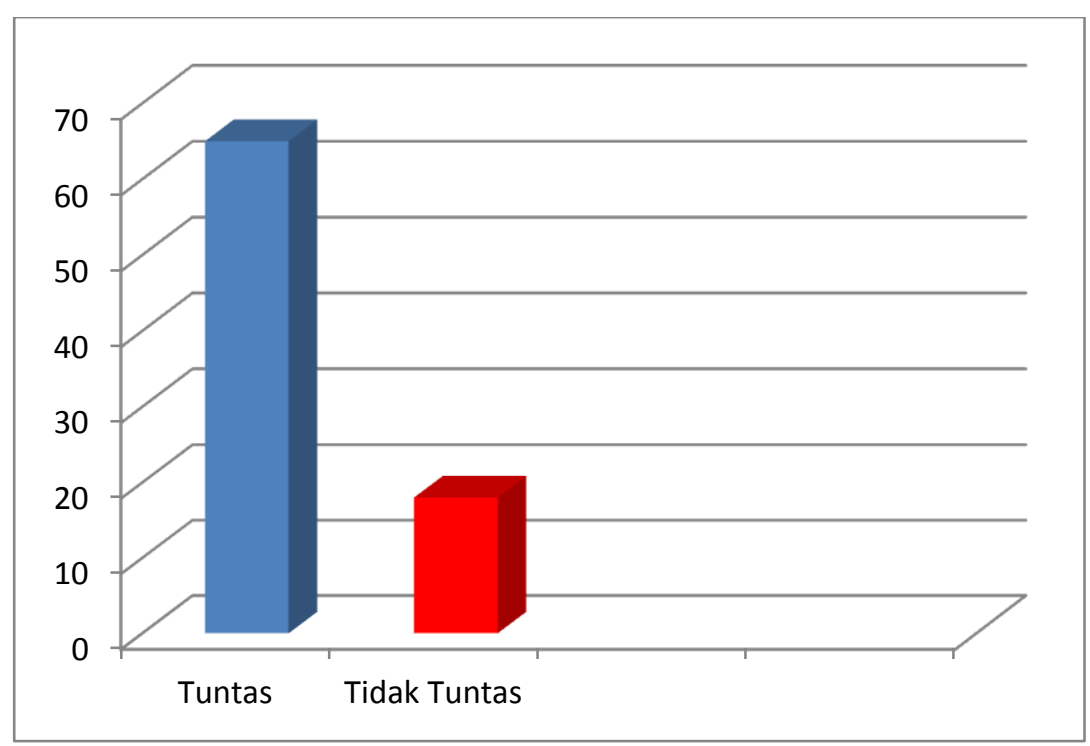

Penerapan pendekatan CTL dalam pembelajaran matematika sangat membantu keterampilan dasar mengajar guru. Guru berperan sebagai pengelola proses KBM, moderator, motivator, Fasilitator, dan evaluator. Pembelajaran tidak berpusat pada guru, melainkan siswa berperan aktif terlibat dalam proses pembelajaran. Siswa belajar melalui belajar kelompok, diskusi, saling mengoreksi untuk memecahkan masalah dan menemukan sesuatu yang berguna bagi dirinya..

Penerapan pendekatan CTL mampu meningkatkan hasil belajar siswa. Pada siklus I rerata hasil belajar sebesar 68, dengan nilai tertinggi 100 dan terendah 45. Persentase belajar klasikal sebesar 63\%. Pada siklus II terjadi peningkatan hasil belajar dengan rerata 74, dengan nilai tertinggi 100 dan terendah 55. Persentase ketuntasan belajar klasikal adalah $82 \%$.

Berdasarkan hasil observasi keterampilan guru, aktivitas belajar siswa, dan hasil belajar siswa pada siklus I dan II telah mencapai indikator keberhasilan.

\section{Kesimpulan dan Saran}

\subsection{Kesimpulan}

Berdasarkan penelitian yang dilakukan di MI Al- Ma'arif Kota Sorong dengan menerapkan pendekatan Contextual Teaching and Learning (CTL) dalam kegiatan belajar mengajar mata pelajaran matematika materi berbagai bentuk pecahan pada kelas III dengan tujuan untuk meningkatkan kualitas pembelajaran, dapat disimpulkan bahwa Penerapan pendekatan CTL mampu meningkatkan aktivitas siswa dalam pembelajaran. 
Hal ini ditunjukkan dengan perolehan rata-rata persentase skor pada siklus I sebesar 70,5\% dengan kriteria baik. Pada siklus II rata-rata persentase skor meningkat menjadi 85,5\% dengan kriteria baik sekali. Aktivitas siswa meliputi : persiapan siswa sebelum mengikuti KBM, keantusiasan siswa dalam mendengarkan penjelasan guru, keaktifan dalam bertanya, menjawab, mengemukakan pendapat, keterlibatan dalam belajar kelompok, kemampuan siswa dalam kegiatan inquiry, kemampuannya dalam mengerjakan evaluasi, dan keterlibatan siswa dalam melakukan refleksi.

Penerapan pendekatan CTL mampu meningkatkan hasil belajar siswa hal ini ditunjukkan dengan rata-rata nilai pada siklus I sebesar 68 mengalami peningkatan menjadi 74 pada siklus II. Ketuntasan belajar klasikal pada siklus I sebesar $63 \%$ meningkat menjadi $82 \%$ pada siklus II.

\subsection{Saran}

Pembelajaran hendaknya dikaitkan dengan kehidupan nyata siswa. Penerapan pendekatan CTL dalam pembelajaran matematika hendaknya dijadikan referensi sekolah guna meningkatkan hasil belajar siswa sebagai salah satu sarana peningkatan kualitas pembelajaran.

\section{Daftar Pustaka}

Aqib, Zainal. 2009. Penelitian Tindakan Kelas. Bandung: Yrama Widya. Darmadi, Hamid. 2009. Kemampuan Dasar Mengajar. Bandung: Alfabeta.

Depdiknas. 2002. Pendekatan Kontekstual (Contextual Teaching and Learning (CTL)). Jakarta: Direktorat Pendidikan Lanjutan Pertama, Direktorat Jenderal Pendidikan Dasar Menengah.

Eko, Susanto. 2008. http://eko13.wordpress.com/2008/03/18/jenis-datadan- metode- pengumpulan-data/. (11 feb 2012)

Heruman. 2007. Model Pembelajaran Matematika Di Sekolah Dasar. Bandung: Rosda

I, Nyoman Gita.2007. Jurnal Penelitian. Implementasi Pendekatan Kontekstual Untuk Meningkatkan Prestasi Belajar Matematika Di Sekolah Dasar http://www.freewebs.com/santyasa/Lemlit/ PDF_Files/ PENDIDIKAN/AGUSTUS2007/ I_Nyoman_Gita.pdf

Pusat Bahasa.2002. Kamus Besar Bahasa Indonesia. Jakarta: Balai Pustaka Riyanto, Yatim. 2010. Paradigma Baru Pembelajaran. Jakarta: Kencana

Rusman. 2011. Model-model Pembelajaran Mengembangkan Profesionalisme Guru. Jakarta:PT Raja Grafindo Persada

Smith, Mark dkk.2009 Teori Pembelajaran dan Pengajaran. Jogjakarta:Mirza Media Pustaka

Sriyono. 2008. Aktivitas dan Prestasi Belajar. http://ipotes.wordpress.com/2008/05/24/prestasi-belajar/ (11 Feb 2012)

Suliyanto, Joko. 2010. Makalah. Pendekatan Kontekstual dalam Pembelajaran Matematika untuk Meningkatkan Berpikir Kritis pada Siswa Sekolah Dasar. FIP, IKIP PGRI Semarang

Suprijono, Agus. 2010. Cooperative Learning Teori dan Aplikasi PAIKEM. Yogyakarta: Pustaka Pelajar Uno, Hamzah B.2010. Model Pembelajaran.Jakarta: Bumi Aksara.

Winataputra, Udin S. 2003. Strategi Belajar Mengajar. Jakarta: Universitas Terbuka

Yamin, Martinis.2007.Kiat Membelajarkan Siswa. Jakarta: Gaung Persada Press 